\title{
Selective antegrade cerebral perfusion during aortic arch surgery confers survival and neuroprotective advantages
}

\author{
Mohammad Shihata, MD, ${ }^{\mathrm{a}}$ Rohan Mittal, ${ }^{\mathrm{a}}$ A. Senthilselvan, PhD, ${ }^{\mathrm{b}}$ David Ross, MD, ${ }^{\mathrm{a}}$ Arvind Koshal, MD, ${ }^{\mathrm{a}}$ \\ John Mullen, MD, ${ }^{\mathrm{a}}$ and Roderick MacArthur, $\mathrm{MD}^{\mathrm{a}}$
}

Objective: To assess the impact of using antegrade cerebral perfusion during aortic arch surgery on postoperative survival and neurologic outcomes.

\begin{abstract}
Methods: All operations were performed at the same hospital between January 2001 and January 2009. Patients undergoing aortic arch surgery using antegrade cerebral perfusion during deep hypothermia were compared with patients undergoing aortic arch surgery without antegrade cerebral perfusion during the same study period. Multivariable logistic regression and Cox proportional hazards model were used to identify predictors of postoperative cerebrovascular accidents and midterm survival, respectively. There were 46 patients in the antegrade cerebral perfusion group and 78 patients in the non-antegrade cerebral perfusion group.
\end{abstract}

Results: There were no statistically significant differences in age, proportion of emergency operations, or proportion of type A aortic dissection between the 2 groups. There was a statistically significant and clinically important difference in the rates of postoperative cerebrovascular complications ( $2 \%$ antegrade cerebral perfusion vs $13 \%$ non-antegrade cerebral perfusion, $P=.03)$, postoperative duration of mechanical ventilation $(1.15 \pm 0.19$ days antegrade cerebral perfusion vs $2.13 \pm 0.38$ days non-antegrade cerebral perfusion, $P=.02$ ), and 3-year survival ( $93 \%$ antegrade cerebral perfusion vs $78 \%$ non-antegrade cerebral perfusion, $P=.03$ ). Antegrade cerebral perfusion was shown to be a significant predictor of reduced postoperative stroke rates and better survival at 3 years.

Conclusions: Antegrade cerebral perfusion was associated with improved survival and neurologic outcomes in patients undergoing aortic arch surgery, especially for cases requiring prolonged aortic arch repair periods. (J Thorac Cardiovasc Surg 2011;141:948-52)

Surgical management of aortic arch pathology is being performed with increasing frequency and improved short- and long-term outcomes. Several advances in perioperative care and refinements in the conduct of these complex procedures have collectively resulted in the reported improved outcomes. $^{1,2}$ Transient and permanent central nervous system deficits, however, remain a significant risk factor for increased morbidity and mortality after aortic arch surgery. ${ }^{3}$ In this retrospective review of our experience with aortic arch surgery for different pathologies, we aim to determine whether antegrade cerebral perfusion (ACP) was associated with improved postoperative outcomes compared with procedures performed without ACP.

\section{PATIENTS AND METHODS}

This is a retrospective cohort study from a prospective database for the period from January 2001 to January 2009. An institutional ethics review

From the Division of Cardiac Surgery, ${ }^{a}$ Department of Surgery, and Department of Public Health Sciences, Biostatistics, ${ }^{\text {b }}$ University of Alberta, Edmonton, Alberta, Canada.

Disclosures: Authors have nothing to disclose with regard to commercial support. Received for publication April 4, 2010; revisions received June 3, 2010; accepted for publication June 23, 2010; available ahead of print Aug 5, 2010.

Address for reprints: Mohammad Shihata, MD, University of Alberta, Mazankowski

Alberta Heart Institute, Division of Cardiac Surgery 3H2.11 WMC, 8440-112

Street, Edmonton, AB, T6G 2B7 (E-mail: mshihata@gmail.com).

0022-5223/\$36.00

Copyright (c) 2011 by The American Association for Thoracic Surgery doi: 10.1016/j.jtcvs.2010.06.047 board's approval was obtained for the collection and analysis of the data in a retrospective fashion. All operations were performed at the same hospital. The patients were divided into 2 groups according to whether they did or did not have ACP. The primary outcomes of the study were postoperative stroke, 30-day mortality, and 3-year mortality. There was a cohort of 128 aortic arch operations requiring deep hypothermic circulatory arrest (DHCA) (Figure 1). Four patients were excluded from the analysis for developing new neurologic deficits before the surgical repair. Right axillary artery cannulation (AC) was used for ACP in 46 patients. The comparison group comprised 78 consecutive patients requiring aortic arch surgery not using ACP during the same study period. Thirty patients in the comparison group had retrograde cerebral perfusion (RCP) as an adjunct to DHCA.

Several previous reports comparing DHCA alone with RCP did not show significant differences in survival neurologic outcomes. Because of this and sample size reasons, we chose to compare patients receiving $\mathrm{ACP}$ with patients not receiving ACP as opposed to comparing the 3 cerebral protection strategies.

\section{Operative Details}

All operations were performed through a median sternotomy using deep hypothermia as the primary means of organ protection. Deep hypothermia was defined as reaching a core body temperature of $18^{\circ} \mathrm{C}$ to $20^{\circ} \mathrm{C}$ (both nasopharyngeal and urinary bladder temperatures). Cooling was done gradually with a temperature gradient of less than $10^{\circ} \mathrm{C}$ between the perfusate and the core body temperature for a period of 50 to 60 minutes. Achieving electroencephalogram silence has been shown to correlate with the duration of the cooling phase with almost all patients demonstrating electroencephalogram silence after 50 minutes of cooling. ${ }^{4}$ Topical head cooling, cerebral oxygen saturation monitoring via near-infrared spectroscopy, and carbon dioxide flooding of the field were used in all cases. The method of cerebral protection was based on the surgeon's preference. 

Abbreviations and Acronyms
$\mathrm{AC}=$ axillary artery cannulation
$\mathrm{ACP}=$ antegrade cerebral perfusion
$\mathrm{CPB}=$ cardiopulmonary bypass
CVA $=$ cerebrovascular accident
$\mathrm{DHCA}=$ deep hypothermic circulatory arrest
$\mathrm{OR}=$ odds ratio
$\mathrm{RCP}=$ retrograde cerebral perfusion

\section{Technique for Antegrade Cerebral Perfusion}

For the ACP group, a 5-cm incision was performed medial and parallel to the deltopectoral groove on the right side to expose the axillary artery. For type A aortic dissections and reoperations, this was performed before the sternotomy. After full heparinization, an 8-mm graft was sewn in an endto-side fashion to the axillary artery and attached to the arterial limb of the cardiopulmonary bypass (CPB) circuit. Venous drainage was achieved via the right atrial appendage cannulation with a 2-stage venous cannula in a standard fashion. A left ventricular vent through the right superior pulmonary vein was used on all patients in the ACP group. All procedures in the ACP group were performed using an "arch first" technique. Once the desired temperature was reached, the circulation was temporarily discontinued. The innominate artery was then clamped and arterial flow was reestablished at a rate of $10 \mathrm{~mL} / \mathrm{kg} / \mathrm{min}$ and a blood temperature of $16^{\circ} \mathrm{C}$ to $18^{\circ} \mathrm{C}$. When the aortic arch reconstruction is expected to be prolonged, the left carotid and left subclavian arteries were cannulated separately with balloon-tipped catheters for bilateral cerebral and additional spinal cord antegrade perfusion. Myocardial protection was accomplished using a combination of antegrade and retrograde cardioplegia.

The conduct of CPB in the comparison group was achieved using the left or right femoral artery and a 2-stage right atrial cannula. Bicaval venous cannulation was implemented when RCP was used as an adjunct for cerebral protection. ACP was not used in any of the patients in the comparison group.

\section{Statistical Analysis}

For preoperative, intraoperative, and postoperative variables, univariate analysis of dichotomous variables was performed using tests for 2 independent proportions and Fisher's exact tests as appropriate. Continuous data are presented as means and standard deviations, and were analyzed using the Student $t$ test. Multivariable logistic regression was used to identify significant predictors of postoperative cerebrovascular accident (CVA) rates and is expressed in adjusted odds ratios (ORs) with their corresponding $P$ values and exact $95 \%$ confidence intervals. Actuarial survival at 3 years was calculated using the Kaplan-Meier survival analysis. Cox proportional hazards model was used to identify significant predictors of 3-year mortality. Purposeful model building was used for all multivariable analyses by including all variables with $P$ values less than .2 on univariable analysis and clinically important confounders. All statistical analyses were performed using STATA for Windows, version 10 (Stata Corp LP, College Station, Tex).

\section{RESULTS}

The preoperative characteristics were relatively similar between the 2 groups (Table 1). The ACP group had a slightly lower rate of acute type A aortic dissection compared with the control group. This difference was not statistically significant $(37 \%$ vs $41 \%, P=.76)$. The rates of reoperations and chronic obstructive pulmonary disease

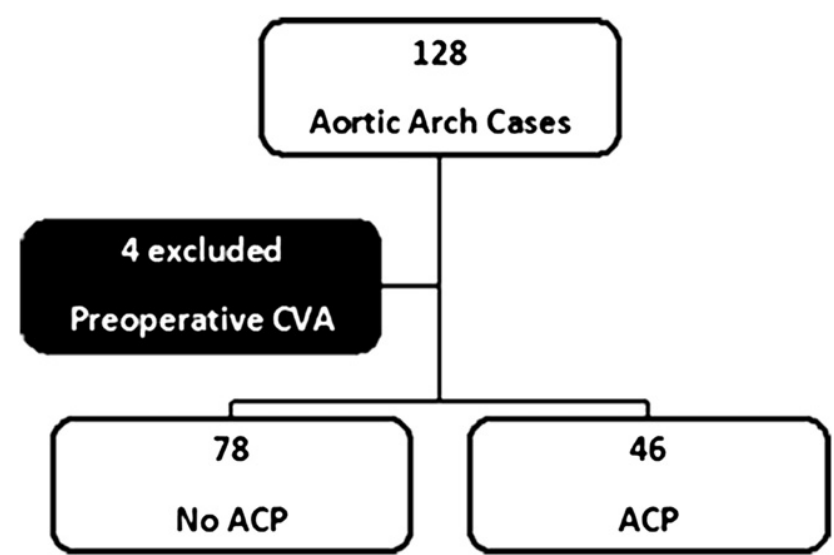

FIGURE 1. Retrospective review of 128 aortic arch cases based on using or not using ACP. ACP, Antegrade cerebral perfusion.

were higher in the ACP group: $24 \%$ versus $18 \%(P=.4)$ and $37 \%$ versus $12 \%(P=.001)$, respectively. Table 2 summarizes the operative findings. The rates of concomitant coronary, aortic valve, and aortic root procedures were higher for the ACP group: $9 \%$ vs $1 \%,(P=.06), 61 \%$ vs $29 \%$ $(P<.001)$, and $37 \%$ vs $14 \%(P<.003)$, respectively. The CPB times and total aortic crossclamp times were significantly longer for the ACP group: $253 \pm 58$ minutes vs $200 \pm 85$ minutes $(P=.0003)$ and $160 \pm 57$ minutes vs $127 \pm 60$ minutes $(P=.003)$, respectively. There were no reported failures to establish $\mathrm{AC}$ as a sole site for arterial flow on CPB in the ACP group. RCP was used in 30 patients $(38 \%)$ of the comparison group.

Postoperative outcomes are summarized in Table 3 . There was a clinically important and statistically significant reduction in the rates of postoperative stroke in the ACP group $(2 \%$ vs $13 \%, P=.031)$. The average need for mechanical ventilatory support was shorter for the ACP group (1.15 \pm 0.19 vs $2.13 \pm 0.38, P<.001)$. There were no statistically significant differences in the rates of postoperative renal failure, total hospital stay, or transfusion requirements. No ipsilateral peripheral neurovascular complications were observed after AC in the ACP group. Actuarial survival at 3 years was $93 \%$ for the ACP group and $78 \%$ for the comparison group $(P=.032)$ (Figure 2). Postoperative CVA was compared using multivariable logistic analysis to adjust for the differences in baseline and operative characteristics (Table 4). ACP was identified as a significant predictor of lower postoperative stroke rate (adjusted OR, 0.07; $P=.03$ ). The presence of documented peripheral vascular disease was significantly associated with postoperative CVA (adjusted OR, 17.6; $P=.005$ ). The use of RCP was found to be protective against postoperative CVA. This effect, however, was not statistically significant (adjusted OR, $0.41 ; P=.39$ ).

Similarly, adjusted hazard ratios for 3-year mortality were compared between the 2 groups using Cox proportional 
TABLE 1. Preoperative patient characteristics

\begin{tabular}{lccc}
\hline & ACP (46) & No ACP (78) & $\boldsymbol{P}$ value \\
\hline Age (y) & 62 & 57.5 & .11 \\
Gender (male) & $63 \%$ & $60 \%$ & .76 \\
Low LVEF $(<50)$ & $9 \%$ & $13 \%$ & .56 \\
Diabetes mellitus & $11 \%$ & $10.3 \%$ & .91 \\
Hypertension & $80 \%$ & $64 \%$ & .055 \\
Type A dissection & $37 \%$ & $41 \%$ & .70 \\
PVD & $8.6 \%$ & $14 \%$ & .41 \\
Reoperations & $24 \%$ & $\mathbf{1 8} \%$ & $\mathbf{. 4 2}$ \\
COPD & $\mathbf{3 7} \%$ & $\mathbf{1 2} \%$ & $\mathbf{. 0 0 1}$ \\
\hline
\end{tabular}

$A C P$, Antegrade cerebral perfusion; $L V E F$, left ventricular ejection fraction; $P V D$, peripheral vascular disease; $C O P D$, chronic obstructive pulmonary disease.

hazards model (Table 5). ACP was found to be associated with better 3-year survival (adjusted hazard ratio 0.07, $P=.01)$.

\section{DISCUSSION}

Despite the major improvements in the outcomes of aortic arch surgery during the last 3 decades, reducing the incidence of postoperative stroke and its associated morbidity and mortality remains a formidable challenge. CVA after aortic arch surgery could be embolic, a result of cerebral hypoperfusion, or a combination of the 2 mechanisms. The reported incidences of postoperative CVA and 30-day mortality range from $2 \%$ to $16 \%$ and $3 \%$ to $23 \%$, respectively. ${ }^{3,5}$ Since its introduction, DHCA has enabled adequate visualization and surgical reconstruction of the aortic arch. ${ }^{6}$ DHCA has been the mainstay for organ protection by significantly reducing the metabolic demand of body organs and allowing for a safe period circulatory arrest. Several adjuncts aiming toward improving cerebral protection were developed in an attempt to extend the safety period that may be required for more complex forms of aortic arch surgery. RCP was first advocated by Ueda and colleagues. ${ }^{7}$ RCP had several theoretic advantages that resulted in a wide early adoption by the cardiac surgery community. These advantages include uniform cooling of the brain, con-

TABLE 2. Operative characteristics

\begin{tabular}{lrrc}
\hline & ACP (46) & No ACP (78) & P value \\
\hline RCP & $0 \%$ & $38 \%$ & $<.001$ \\
CABG & $9 \%$ & $1 \%$ & .06 \\
AVR & $61 \%$ & $29 \%$ & .001 \\
Aortic root replacement & $37 \%$ & $14 \%$ & .003 \\
CPB time & $253(58)$ & $200(85)$ & .0003 \\
Crossclamp & $160(57)$ & $127(60)$ & .0032 \\
Arch time & $41(19)$ & $38(23)$ & .56 \\
Lowest temperature $\left(\mathrm{C}^{\circ}\right)$ & $17.8(2.2)$ & $20.7(5)$ & $<.001$ \\
Hemi arch & $84 \%$ & $87 \%$ & .02 \\
Total arch & $16 \%$ & $13 \%$ & .02 \\
Elephant trunk & $9 \%$ & $0 \%$ & .02 \\
\hline
\end{tabular}

$A C P$, Antegrade cerebral perfusion; $R C P$, retrograde cerebral perfusion; $C A B G$, coronary artery bypass grafting; $A V R$, aortic valve replacement; $C P B$, cardiopulmonary bypass.
TABLE 3. Postoperative outcomes

\begin{tabular}{lccc}
\hline & ACP (46) & No ACP (78) & P value \\
\hline CVA & $2.2 \%$ & $13 \%$ & .031 \\
30-d survival & $96 \%$ & $90 \%$ & .32 \\
Mechanical Ventilation (d) & $1.15(0.19)$ & $2.13(0.38)$ & $<.001$ \\
Renal failure & $18 \%$ & $17 \%$ & .99 \\
\hline$A C P$, Antegrade cerebral perfusion; $C V A$, cerebrovascular accident. Renal failure \\
defined as postoperative serum creatinine $>200 \mu$ mol/L.
\end{tabular}

tinuous nutrient supply at a state of low metabolic demand, and retrograde washout of air and microemboli before resuming a full flow state. ${ }^{8,9}$ Several animal and clinical studies, however, have shown that RCP has a marginal benefit in terms of cerebral capillary blood flow and nutrient supply. ${ }^{10,11}$ In some reports, RCP was associated with a higher incidence of temporary and permanent neurologic deficits. ${ }^{12}$

ACP is associated with improved outcomes and was popularized by Kazui ${ }^{13}$ and Bachet and colleagues. ${ }^{14}$ It has since been increasingly applied with several modifications to its originally described technique. ACP can be instituted by cannulating the arch vessels, right axillary artery, or innominate artery, or a combination of these methods. Multiple animal studies have shown preserved cerebral intracellular $\mathrm{pH}$ and energy stores after extended periods of circulatory arrest when ACP is used. ${ }^{14,15}$ Several clinical studies have demonstrated superior survival and neurologic outcomes when using ACP compared with

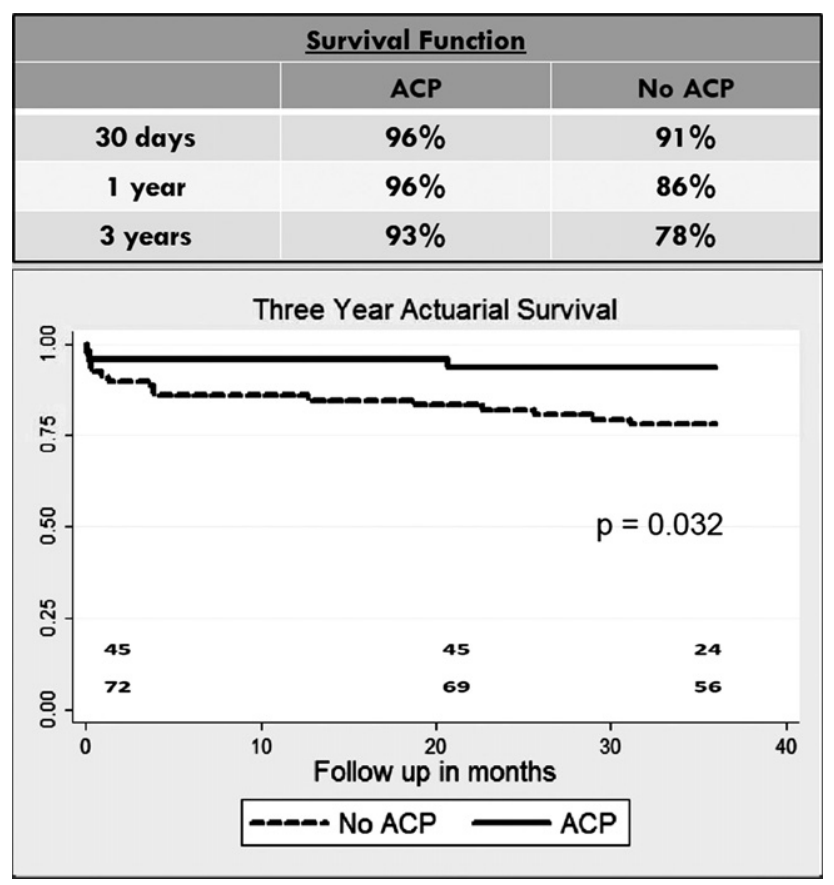

FIGURE 2. Kaplan-Meier survival curves at 30 days, 1 year, and 3 years by study group. $A C P$, Antegrade cerebral perfusion; $C V A$, cerebrovascular accident. 
TABLE 4. Multivariable logistic regression of postoperative cerebrovascular accident

\begin{tabular}{lllcc}
\hline \multicolumn{1}{c}{ Predictor } & \multicolumn{1}{c}{$\begin{array}{c}\text { Univariable } \\
(\text { OR })(\mathbf{C I})\end{array}$} & $\begin{array}{c}\boldsymbol{P} \\
\text { value }\end{array}$ & $\begin{array}{c}\text { Multivariable } \\
(\mathbf{O R})(\mathbf{C I})\end{array}$ & $\begin{array}{c}\boldsymbol{P} \\
\text { value }\end{array}$ \\
\hline ACP & $0.14(0.02-1.08)$ & .06 & $0.06(0.01-0.81)$ & .03 \\
Age & $1.01(0.97-1.06)$ & .53 & - & - \\
Gender (F) & $0.77(0.22-2.7)$ & .69 & - & - \\
Type A dissection & $1.61(0.5-5.3)$ & .44 & $4.29(0.65-28.3)$ & .13 \\
Reoperation & $0.77(0.16-3.78)$ & .75 & - & - \\
PVD & $7.21(1.9-27)$ & .003 & $17.6(2.4-123)$ & .005 \\
DM & $0.76(0.09-6.4)$ & .8 & - & - \\
HTN & $0.56(0.17-1.9)$ & .35 & - & - \\
COPD & $0.32(0.04-2.6)$ & .28 & - & - \\
CPB time & $1.00(0.99-1.01)$ & .40 & - & - \\
Crossclamp & $1.00(0.99-1.01)$ & .59 & - & - \\
Arch time & $1.00(0.97-1.02)$ & .88 & $1.02(0.99-1.04)$ & .24 \\
RCP & $1.05(0.26-4.2)$ & .95 & $0.41(0.05-3.2)$ & .39 \\
Temperature & $1.05(0.94-1.2)$ & .37 & $0.96(0.7-1.3)$ & .78 \\
\hline
\end{tabular}

$O R$, Odds ratio; $C I$, confidence interval; $A C P$, antegrade cerebral perfusion; $P V D$, peripheral vascular disease; $D M$, diabetes mellitus; $H T N$, hypertension; $C O P D$, chronic obstructive pulmonary disorder; $C P B$, cardiopulmonary bypass, $R C P$, retrograde cerebral perfusion.

historical outcomes. ${ }^{5,16,17}$ To date, however, there is no consensus on the best cerebral protection strategy among surgeons dealing with large volumes of aortic arch pathologies. Several retrospective studies have been done comparing ACP with DHCA alone or DHCA plus RCP. The reports have been inconsistent and somewhat contradictory. ${ }^{18-20}$ One randomized controlled trial was identified in the literature. This study was designed to compare the 3 strategies for cerebral protection ${ }^{21}$ and did not show any difference in postoperative stroke or hospital mortality. A major limitation of this trial was the low number of patients in each arm (10 patients). In a recent review article, the authors compared 16 clinical and animal studies comparing the 3 cerebral protection strategies. The conclusion was in support of ACP as a superior method of cerebral protection. $^{22}$

The current study retrospectively reviewed our experience with ACP to determine whether this adjunct was associated with reduced postoperative stroke and mortality rates. Although ACP was used more recently at the University of Alberta, all cases were done in a relatively short study period, negating a potential era effect. Cerebral perfusion via the right axillary artery was used in all patients in the AC group. Separate cannulation of the left common carotid and left subclavian arteries was resorted to when the arch time was expected to exceed 35 to 40 minutes. In a recent review, unilateral and bilateral cerebral perfusion techniques during aortic arch surgery were compared. ${ }^{23} \mathrm{~A}$ total of 3548 patients were reviewed, and the authors concluded that "while unilateral perfusion allowed approximately 30 to 50 minutes, bilateral perfusion allowed 86 to more than 164 minutes of ACP with an acceptably low CVA rate
TABLE 5. Cox proportional hazards model for 3-year survival

\begin{tabular}{lcccc}
\hline \multicolumn{1}{c}{ Predictor } & $\begin{array}{c}\text { Univariable } \\
(\text { HR })(\mathbf{C I})\end{array}$ & $\begin{array}{c}\boldsymbol{P} \\
\text { value }\end{array}$ & $\begin{array}{c}\text { Multivariable } \\
(\text { HR })(\mathbf{C I})\end{array}$ & $\begin{array}{c}\boldsymbol{P} \\
\text { value }\end{array}$ \\
\hline ACP & $0.29(0.08-0.97)$ & .046 & $0.07(0.01-0.52)$ & .01 \\
Gender (F) & $2.11(0.87-5.09)$ & .09 & $2.97(0.84-10.4)$ & .09 \\
Age & $1.03(0.99-1.07)$ & .07 & $1.06(0.99-1.12)$ & .07 \\
DM & $1.57(0.46-5.37)$ & .47 & - & - \\
HTN & $1.74(0.58-5.21)$ & .32 & - & - \\
PVD & $2.13(0.71-6.41)$ & .18 & $4.16(1.02-16.8)$ & .046 \\
Type A dissection & $1.03(0.42-2.52)$ & .95 & - & - \\
COPD & $0.64(0.18-2.18)$ & .48 & - & - \\
Postoperative RF & $2.52(0.87-7.26)$ & .09 & $1.1(0.29-4.16)$ & .88 \\
RCP & $1.28(0.49-3.32)$ & .62 & - & - \\
Temperature & $1.05(0.97-1.14)$ & .30 & - & - \\
AVR & $0.34(0.11-1.00)$ & .05 & $4.9(0.59-40.9)$ & .14 \\
CPB time (min) & $1.00(0.99-1.01)$ & & - & - \\
Crossclamp & $1.00(0.98-1.00)$ & .41 & - & - \\
Arch time (min) & $1.02(1.00-1.04)$ & .04 & $1.026(1.00-1.05)$ & .036 \\
\hline$H R$, Hazard ratio; $C I$, confidence interval; $A C P$, antegrade cerebral perfusion; $D M$, \\
diabetes mellitus; $H T N$, hypertension; $P V D$, peripheral vascular disease; $C O P D$, \\
chronic obstructive pulmonary disease; $R F$, renal failure; $R C P$, retrograde cerebral \\
perfusion; $A V R$, aortic valve replacement; $C P B$, cardiopulmonary bypass. Tempera- \\
ture is the core body temperature during circulatory arrest or low flow states.
\end{tabular}

$(<5 \%)$." There are increasing reports on performing aortic arch surgery using ACP under moderate hypothermia at a core body temperature of $28^{\circ} \mathrm{C}$ with postoperative neurologic complication rates comparable to most contemporary reports where deep hypothermia was used.

The use of the right axillary artery has been proven to be safe and advantageous in aortic arch surgery. ${ }^{24}$ In addition to providing ACP, these potential advantages include avoiding manipulation of the proximal arch vessels where atherosclerotic plaques tend to be concentrated and instituting CPB before sternal reentry in complex reoperations. Furthermore, the right axillary artery is rarely involved in a dissection process at such a distal location. The use of a side graft has been shown to reduce the rates of postoperative stroke and cannulation-related morbidity compared with direct cannulation. ${ }^{25}$ In our study, the AC group had longer ischemia times, a higher rate of reoperation, and more complex aortic arch procedures. Despite this, the AC group had better neurologic outcomes and better survival at 30 days and 1 year. One-year survival has been shown to correlate favorably with midterm survival.

\section{CONCLUSIONS}

Despite the relatively small sample size, ACP was associated with clinically important and statistically significant improvements in the rates of postoperative CVA and mortality. The conclusion of our study is still limited by the inherent biases of a retrospective analysis. However, there is a growing body of evidence supporting ACP as a superior cerebral protection strategy, especially when used for cases requiring prolonged aortic arch reconstruction periods. 
The authors thank Dr Scott LeMaire from Baylor College of Medicine and the Texas Heart Institute and Mary Ann James from the APPROACH database at the University of Alberta for valuable contributions to this article.

\section{References}

1. Ergin MA, Griepp EB, Lansman SL, et al. Hypothermic circulatory arrest and other methods of cerebral protection during operations on the thoracic aorta. J Card Surg. 1994;9:525-37.

2. Coselli JS, Buket S, Djukanovic B. Aortic arch operation: current treatment and results. Ann Thorac Surg. 1995;59:19-27.

3. Apostolakis E, Akinosoglou K. The methodologies of hypothermic circulatory arrest and of antegrade and retrograde cerebral perfusion for aortic arch surgery. Ann Thorac Cardiovasc Surg. 2008;14:138-48.

4. Stecker MM, Cheung AT, Pochettino A, et al. Deep hypothermic circulatory arrest: I. Effects of cooling on electroencephalogram and evoked potentials. Ann Thorac Surg. 2001;71:14-21.

5. Kazui T, Washiyama N, Muhammad BA, et al. Improved results of atherosclerotic arch aneurysm operations with a refined technique. J Thorac Cardiovasc Surg. 2001;121:491-9.

6. Griepp RB, Ergin MA, McCullough JN, et al. Use of hypothermic circulatory arrest for cerebral protection during aortic surgery. J Card Surg. 1997;12:312-21.

7. Ueda Y, Miki S, Kusuhara K, et al. Surgical treatment of aneurysm or dissection involving the ascending aorta and aortic arch, utilizing circulatory arrest and retrograde cerebral perfusion. J Cardiovasc Surg (Torino). 1990;31:553-8.

8. Raskin SA, Coselli JS. Retrograde cerebral perfusion: overview, techniques and results. Perfusion. 1995;10:51-7.

9. Coselli JS, LeMaire SA. Experience with retrograde cerebral perfusion during proximal aortic surgery in 290 patients. J Card Surg. 1997;12:322-5.

10. Ehrlich MP, Hagl C, McCullough JN, et al. Retrograde cerebral perfusion provides negligible flow through brain capillaries in the pig. $J$ Thorac Cardiovasc Surg. 2001;122:331-8.

11. Haverich A, Hagl C. Organ protection during hypothermic circulatory arrest. J Thorac Cardiovasc Surg. 2003;125:460-2.

12. Hagl C, Ergin MA, Galla JD, et al. Neurologic outcome after ascending aortaaortic arch operations: effect of brain protection technique in high-risk patients. J Thorac Cardiovasc Surg. 2001;121:1107-21.
13. Kazui T. Simple and safe cannulation technique for antegrade selective cerebral perfusion. Ann Thorac Cardiovasc Surg. 2001;7:186-8.

14. Bachet J, Guilmet D, Goudot B, et al. Cold cerebroplegia. A new technique of cerebral protection during operations on the transverse aortic arch. $J$ Thorac Cardiovasc Surg. 1991;102:85-93.

15. Kazui T, Kimura N, Yamada O, Komatsu S. Surgical outcome of aortic arch aneurysms using selective cerebral perfusion. Ann Thorac Surg. 1994;57:904-11.

16. Sanioglu S, Sokullu O, Ozay B, et al. Safety of unilateral antegrade cerebral perfusion at 22 degrees C systemic hypothermia. Heart Surg Forum. 2008;11: E184-7.

17. Etz CD, Plestis KA, Kari FA, et al. Axillary cannulation significantly improves survival and neurologic outcome after atherosclerotic aneurysm repair of the aortic root and ascending aorta. Ann Thorac Surg. 2008;86:441-7.

18. Apostolakis E, Koletsis EN, Dedeilias P, et al. Antegrade versus retrograde cerebral perfusion in relation to postoperative complications following aortic arch surgery for acute aortic dissection type A. J Card Surg. 2008;23:480-7.

19. Gulbins H, Pritisanac A, Ennker J. Axillary versus femoral cannulation for aortic surgery: enough evidence for a general recommendation? Ann Thorac Surg. 2007; 83:1219-24.

20. Matalanis G, Hata M, Buxton BF. A retrospective comparative study of deep hypothermic circulatory arrest, retrograde, and antegrade cerebral perfusion in aortic arch surgery. Ann Thorac Cardiovasc Surg. 2003;9:174-9.

21. Svensson LG, Nadolny EM, Penney DL, et al. Prospective randomized neurocognitive and S-100 study of hypothermic circulatory arrest, retrograde brain perfusion, and antegrade brain perfusion for aortic arch operations. Ann Thorac Surg. 2001;71:1905-12.

22. Barnard J, Dunning J, Grossebner M, Bittar MN. In aortic arch surgery is there any benefit in using antegrade cerebral perfusion or retrograde cerebral perfusion as an adjunct to hypothermic circulatory arrest? Interact Cardiovasc Thorac Surg. 2004;3:621-30

23. Malvindi PG, Scrascia G, Vitale N. Is unilateral antegrade cerebral perfusion equivalent to bilateral cerebral perfusion for patients undergoing aortic arch surgery? Interact Cardiovasc Thorac Surg. 2008;7:891-7.

24. Moizumi Y, Motoyoshi N, Sakuma K, Yoshida S. Axillary artery cannulation improves operative results for acute type a aortic dissection. Ann Thorac Surg. 2005; $80: 77-83$.

25. Sabik JF, Nemeh H, Lytle BW, et al. Cannulation of the axillary artery with a side graft reduces morbidity. Ann Thorac Surg. 2004;77:1315-20. 